\title{
Treatment of Genital Psoriasis: A Systematic Review
}

Kristen M. Beck • Eric J. Yang • Isabelle M. Sanchez · Wilson Liao

Received: June 14, 2018 / Published online: August 25, 2018

(C) The Author(s) 2018

\section{ABSTRACT}

Genital psoriasis affects approximately $63 \%$ of psoriasis patients at least once in their lifetime. More than any other area on the body, genital lesions significantly impair patients' psychologic well-being and quality of life. We aimed to systematically review the published evidence on the safety, efficacy, and tolerability of treatments of genital psoriasis and synthesize the available clinical data. A total of 1 randomized controlled trial, 11 open-label studies, and 26 case reports were included in our analysis, representing a total of 458 patients, of which 332 were adults and 126 were children. Topical corticosteroids were commonly used first-line for genital psoriasis and were well tolerated. Nonsteroidal agents, such as topical calcineurin inhibitors or vitamin D analogs, were also efficacious, but were often irritating. One systemic agent, ixekizumab, demonstrated efficacy in

Kristen M. Beck and Eric J. Yang contributed equally to the work.

Enhanced digital features To view enhanced digital features for this article go to https://doi.org/10.6084/ m9.figshare.6950072.

K. M. Beck ( $\varangle)$ - E. J. Yang · I. M. Sanchez - W. Liao Department of Dermatology, UCSF Medical Center, San Francisco, CA, USA

e-mail: Kristen.Beck@ucsf.edu reducing genital psoriasis symptoms in a large, randomized, placebo-controlled trial. Various systemic and topical medications may improve genital psoriasis lesions, but there is a lack of high-quality evidence to guide clinical decisionmaking. Specific reporting of efficacy for genital psoriasis in larger controlled studies of psoriasis treatments are necessary to improve the available evidence regarding the optimal treatment regimen for genital psoriasis.

Keywords: Genital psoriasis; Psoriasis; Therapy; Treatment

\section{INTRODUCTION}

Sixty-three percent of adults with psoriasis develop psoriatic lesions in the genital area at least once during their lifetime [1]. In the presence of inverse psoriasis, the prevalence of genital psoriasis increases to approximately 79\% $[2,3]$. In $2-5 \%$ of psoriasis patients, lesions only occur in the genital region [3]. Genital psoriasis can occur in all age groups, from newborns to geriatric patients, with a slight predilection for younger male patients with relatively severe disease [4]. In children under 2 years of age, genital psoriasis typically presents as intense well-demarcated erythema in the diaper area, termed napkin psoriasis $[5,6]$. 
Patients with psoriasis lesions in their genital area experience significantly worse quality of life than patients with psoriasis on any other areas, particularly with respect to pruritus, sexual function, sexual health, sexual distress, avoidance of sexual relationships, embarrassment, shame, and psychologic depression [4, 7-9].

Despite the high prevalence of genital psoriasis, almost half of patients with genital lesions do not discuss their symptoms with their physician $[8,10,11]$. Lack of communication and awareness about genital psoriasis in the healthcare environment may result in underdiagnosed and under-treated genital psoriasis, subsequently increasing the risk of inappropriate self-treatment [10].

Although there are many effective treatments in the therapeutic armamentarium for psoriasis, treatment of lesions on the genitalia and surrounding skin folds remains challenging. Topical treatments have increased penetration through the thin, sensitive, and often occluded genital skin, increasing the risk of side effects from common psoriasis medications [12]. A review of the literature in 2011 found a lack of evidence regarding the efficacy and safety of various treatments for genital psoriasis [3]. This review summarizes the most current literature regarding the efficacy and safety of available therapies for psoriasis affecting the genital skin.

\section{METHODS}

A literature search using the MEDLINE and Embase health literature databases was conducted using the terms ("psoriasis") AND ("penile" OR "penis" OR "genital*" OR "glans" OR "scrotal" OR "scrotum" OR "anal" OR "diaper" OR "napkin" OR "shaft" OR "foreskin" OR "prepuce" OR "perianal" OR "vulva*" OR "labia" OR "labium" OR "groin" OR "preputial" OR "penoscrotal"). Two independent reviewers identified the included articles (EY, IS) and extracted information. The review methods were established prior to the conduct of the review and did not deviate during the course of the study. Articles were included if they included patients with psoriasis or psoriasiform napkin dermatitis affecting the genital area, discussed the results of treatment with respect to the genital lesions, and were published prior to 31 July 2018. Studies were excluded if they did not study genital psoriasis, did not discuss the results of treatment in the genital region, were in a foreign language, were conference abstracts, or were a review or meta-analysis. Study results were extracted using a standardized data form recording information on the publication date, type of psoriasis, site, age and gender of patients, and reported efficacy and adverse events. In addition, the quality of all studies was rated based on the Oxford Centre for Evidence-Based Medicine Levels of Evidence rating scheme [13].

The article is based on previously conducted studies and does not contain any studies with human participants or animals performed by any of the authors.

\section{RESULTS}

A total of 1964 potentially relevant unique citations were identified from our literature search (Fig. 1). Of these, 128 articles were selected for further evaluation based on the relevance of their title and abstract. A total of 32 articles examining the treatment of genital psoriasis were ultimately included in this study. Table 1 summarizes the data for adults. Table 2 summarizes the findings for infants and children.

\section{Treatments for Genital Psoriasis in Adults}

A total of 21 articles examined treatment outcomes for adults with genital psoriasis (Table 1), including 1 randomized controlled trial (grade 1), 8 open-label studies (grade 4), and 16 case reports (grade 5), representing a total of 332 patients. Of these, topical corticosteroids were used in the regimen of 201 patients for successful treatment (Table 2). Low-potency topical steroids were used in 132 patients, moderatepotency steroids were used in 120 patients, and high-potency steroids were used in 15 patients. Antifungal medications were used as part of 


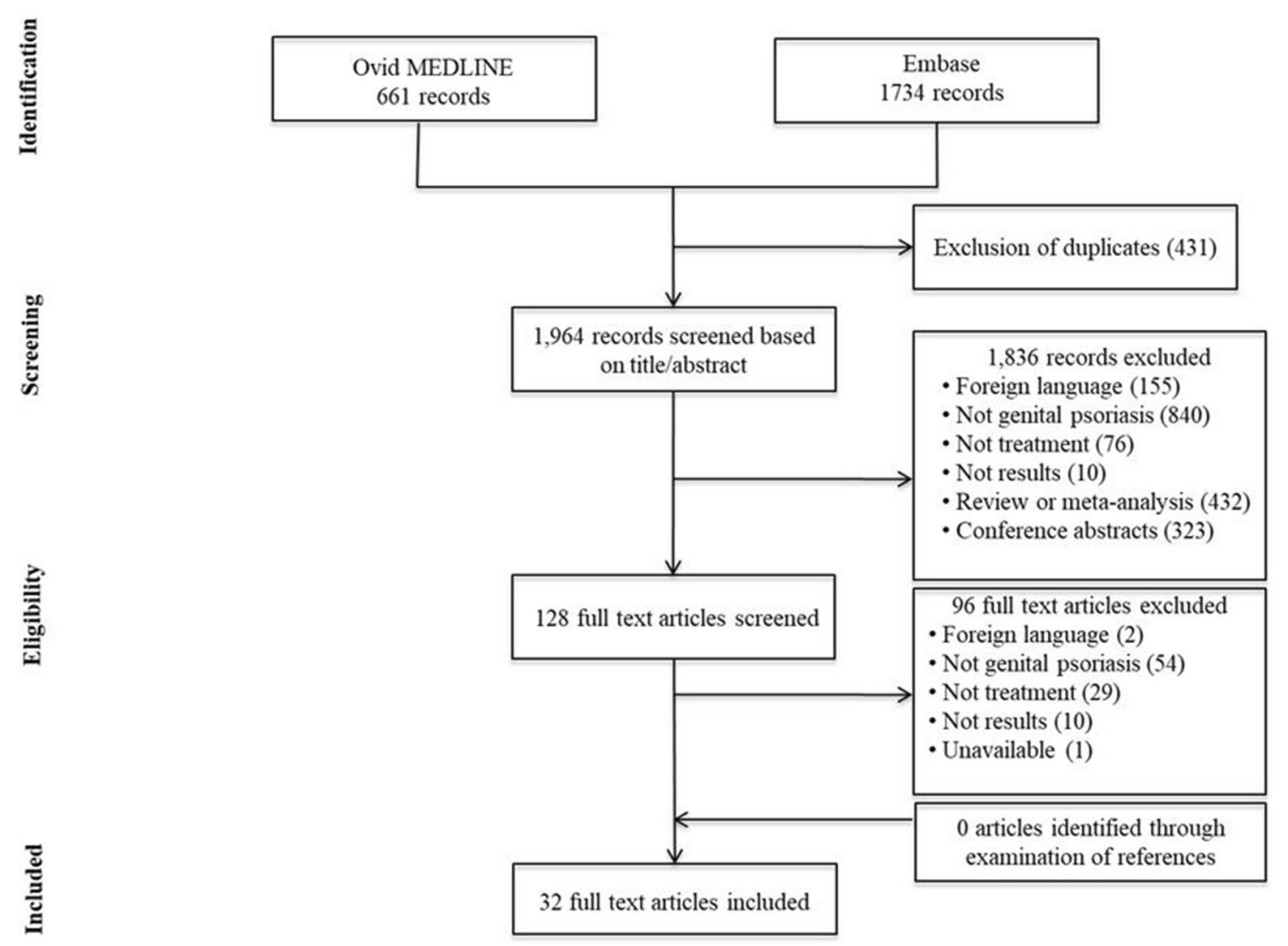

Fig. 1 Genital psoriasis: study selection for treatment

successful treatment in 3 patients, while coal tar preparations were effective in clearing genital lesions in 126 patients. Topical tacrolimus $0.1 \%$ ointment resulted in significant improvement in genital lesions in 38 patients across 4 openlabel studies (grade 4) and 2 case reports (grade 5). Tacrolimus was fairly well tolerated by most patients, with side effects of mild pruritus and/ or burning sensation of limited duration. However, use precipitated extreme irritation in one case report, requiring discontinuation of therapy [14]. Other agents used for successful treatment of genital psoriasis include topical cyclosporine, which was well tolerated in three patients [15].

Vitamin D preparations were used successfully in 40 patients, often in combination with topical corticosteroids for genital psoriasis [16-18]. Additional reports of vitamin D preparation use in genital psoriasis patients exist in the literature; these studies often do not report outcomes specifically for the genital area. A randomized, double-blind, head-to-head comparison (grade 1) of calcitriol ointment $3 \mu \mathrm{g} / \mathrm{g}$ taken twice daily was compared with tacrolimus ointment $0.3 \mathrm{mg} / \mathrm{g}$ taken twice daily for 6 weeks in 49 patients with either facial or genitofemoral psoriasis [19]. Of these patients, five had genital psoriasis; two were treated with calcitriol, and three were treated with tacrolimus. Both treatments were well tolerated in the study, and tacrolimus treatment resulted in a more significant reduction of target lesion size, but results were not stratified for lesions on the face and genitalia.

In addition to topical treatments, several injectable and oral medications have been reported to successfully clear genital lesions of psoriasis (Table 3). Ixekizumab, an IL-17A inhibitor approved for the treatment of moderateto-severe psoriasis and active psoriatic arthritis [20], is the first biologic to report formal clinical 


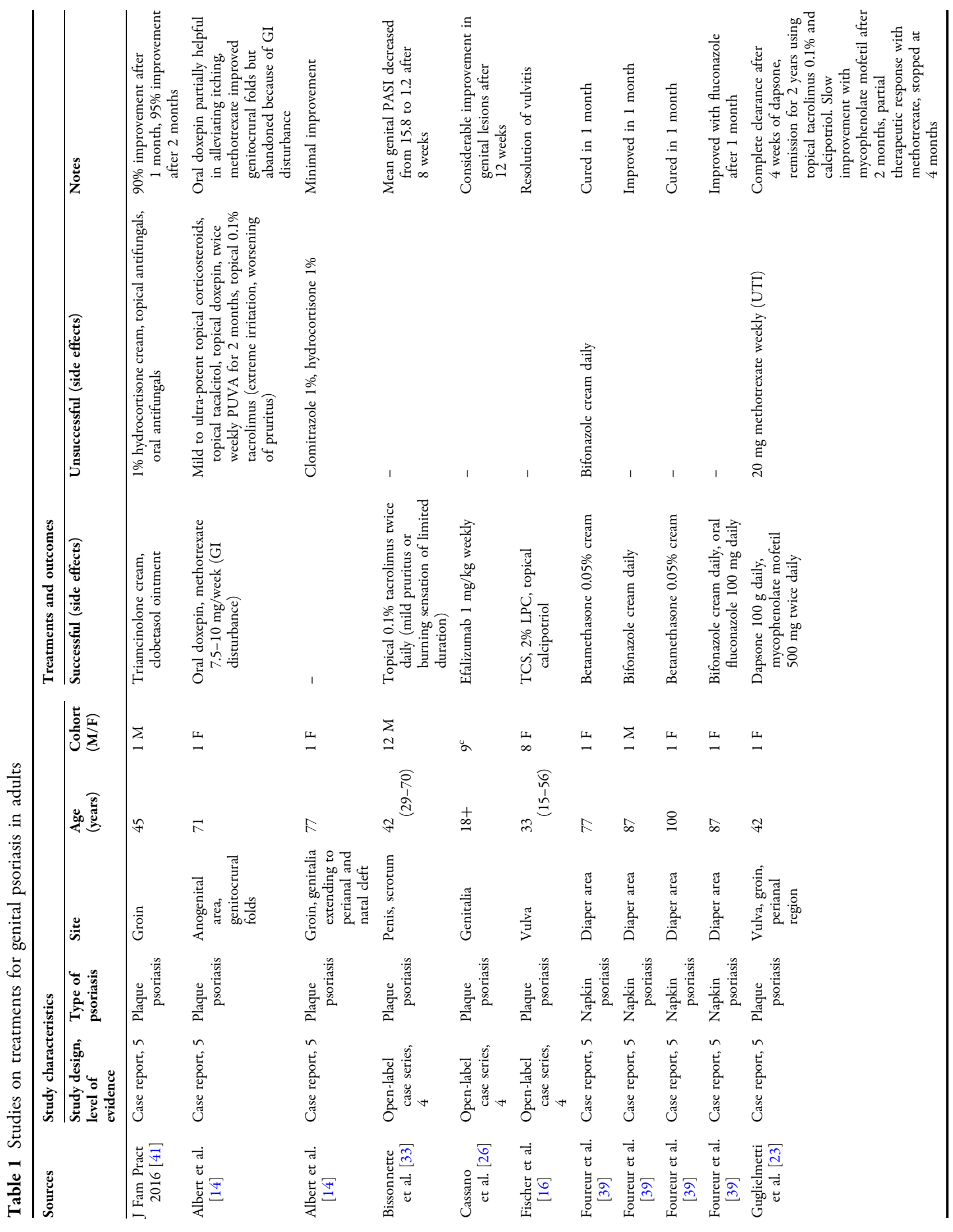




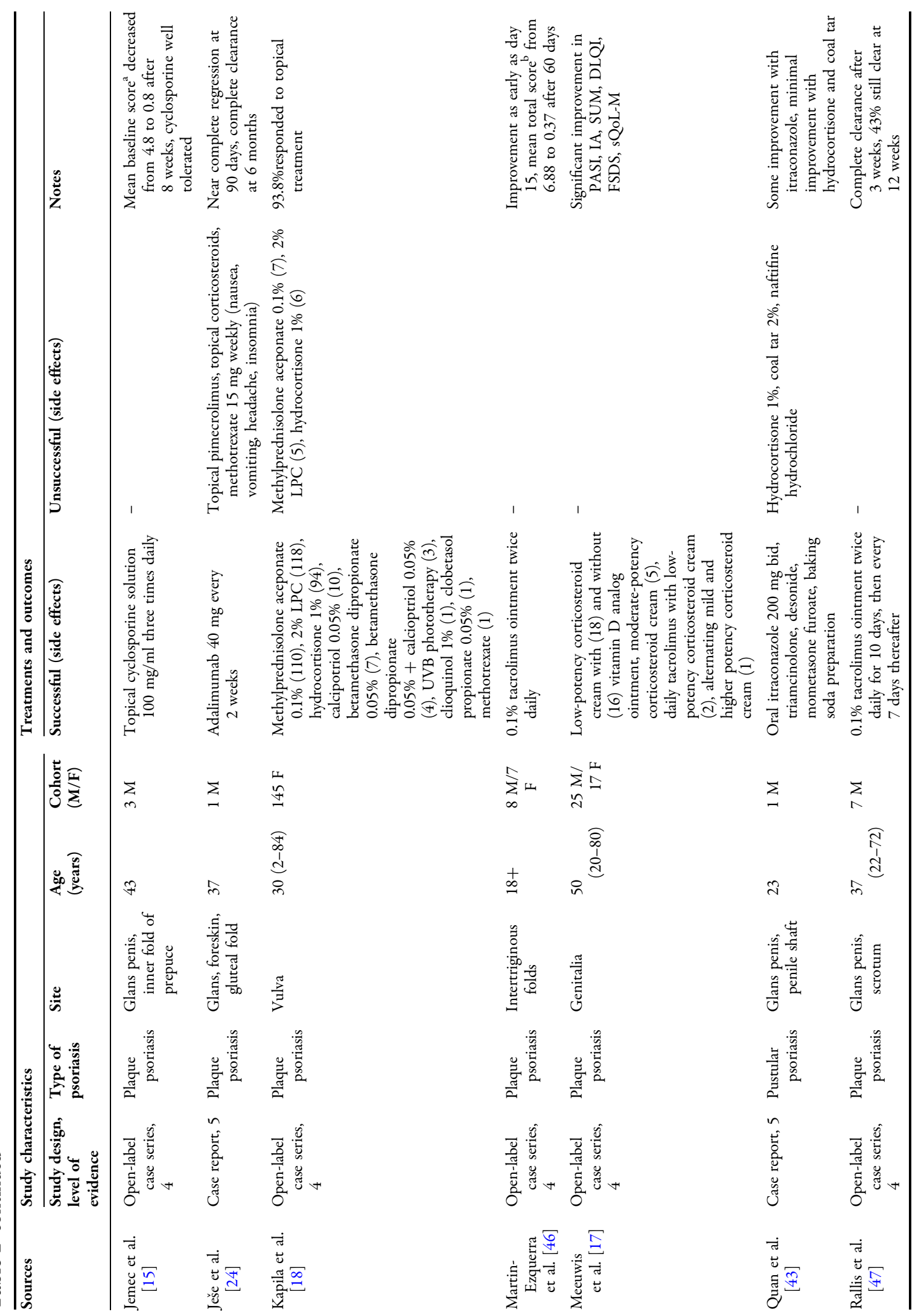




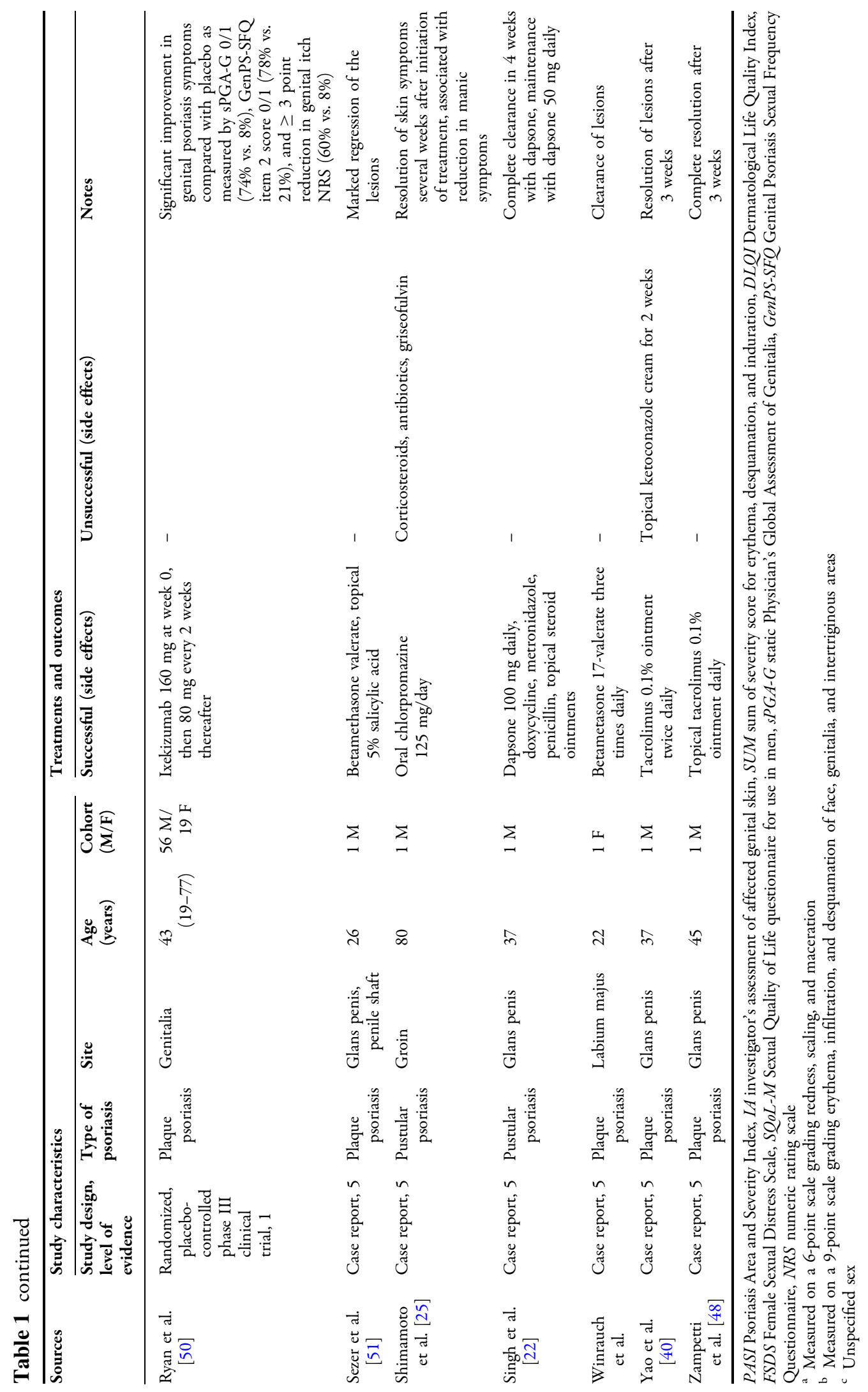




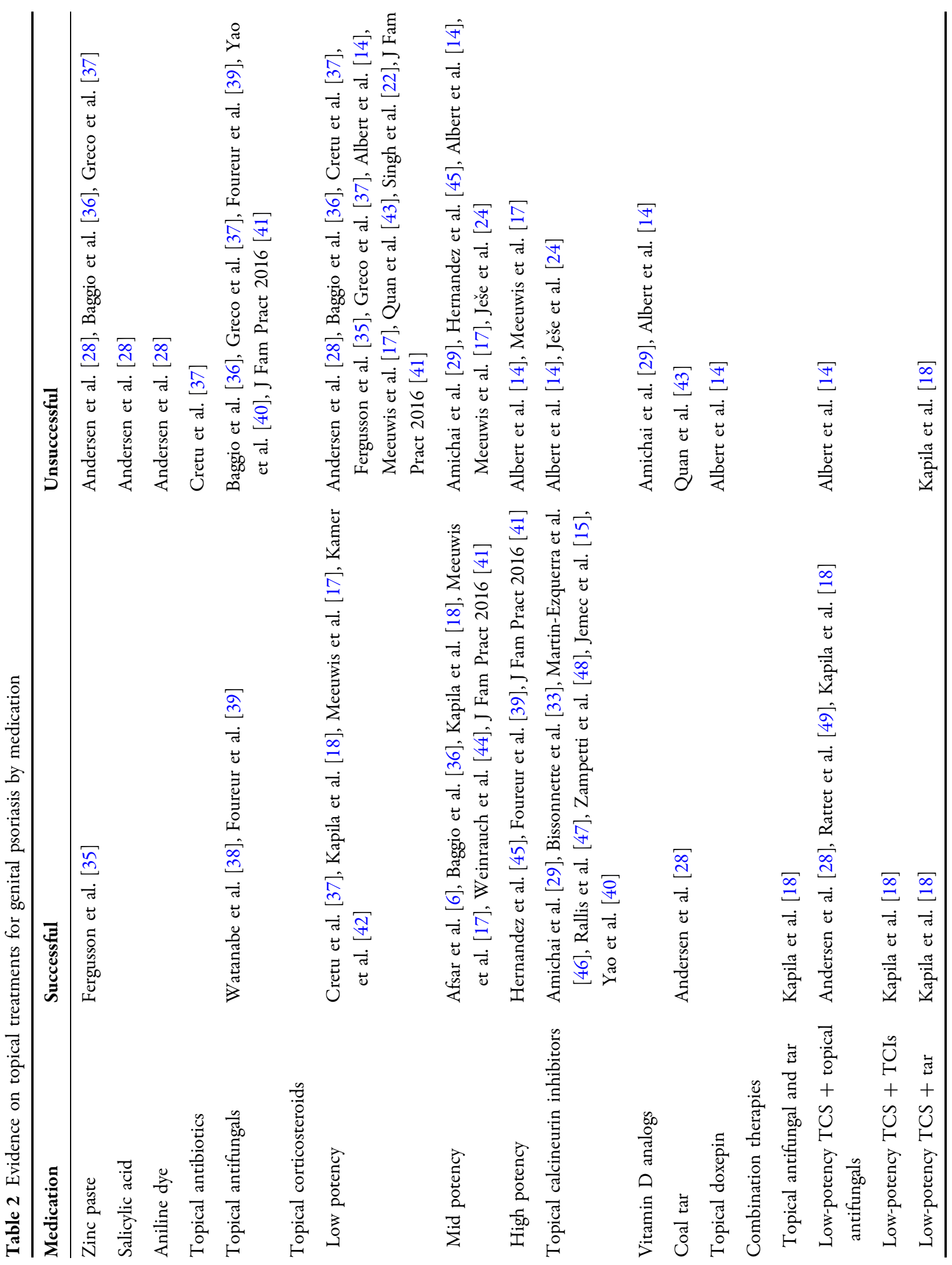




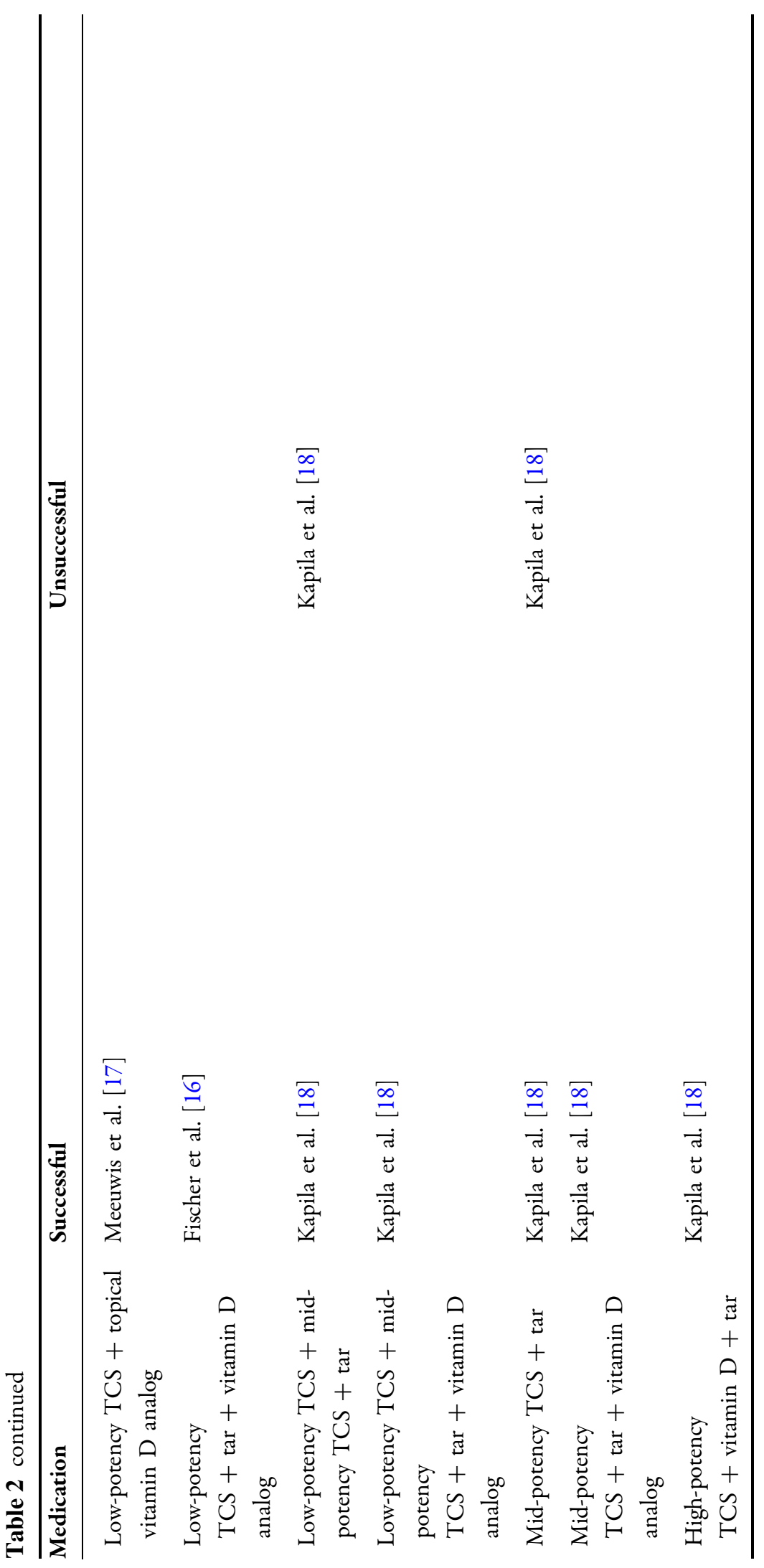


Table 3 Evidence on systemic treatments for genital psoriasis by medication

\begin{tabular}{lll}
\hline Medication & Successful & Unsuccessful \\
\hline $\begin{array}{l}\text { Phototherapy } \\
\text { UVB phototherapy }\end{array}$ & Kapila et al. [18] & Albert et al. [14] \\
PUVA & & \\
Immunosuppressants & & \\
Mycophenolate mofetil & Guglielmetti et al. [23] & Guglielmetti et al. [23], Ješe et al. [24] \\
Methotrexate & Albert et al. [14], Kapila et al. [18] & \\
Biologics & & \\
Adalimumab & Ješe et al. [24] & J Fam Pract 2016 [41] \\
Ixekizumab & Ryan et al. [50] & Singh et al. [22] \\
Efalizuma $b^{\text {a }}$ & Cassano et al. [26] & \\
Oral antifungals & Foureur et al. [39], Meeuwis et al. [17] & \\
Oral antibiotics & Quan et al. [43] & \\
Dapsone & Guglielmetti et al. [23], Singh et al. [22] & \\
Doxepin & Albert et al. [14] & Cretu et al. [37] \\
Antihistamines & Cretu et al. [37] & \\
Antipsychotics & Shimamoto et al. [25] & \\
Calcium gluconate & & \\
\hline
\end{tabular}

a Formerly available treatment

trial data for the treatment of genital psoriasis [21]. In this randomized, double-blind, placebocontrolled phase III trial (grade 1), adult subjects with moderate-to-severe genital psoriasis were randomized to receive either placebo $(n=74)$ or ixekizumab $160 \mathrm{mg}$ subcutaneously at week 0 followed by $80 \mathrm{mg}$ every 2 weeks thereafter $(n=75)$. The primary outcome of patients achieving static Physician's Global Assessment of Genitalia score of "clear" or "minimal" (sPGA-G 0/1) by week 12 was met by significantly more subjects on ixekizumab treatment than placebo (74\% vs. $8 \%)$. Additionally, significantly more patients treated with ixekizumab reported improved sexual activity as measured by Genital Psoriasis Sexual Frequency Questionnaire (GenPS-SFQ) item 2 score $0 / 1$ (78\% vs. $21 \%)$ and clinically meaningful reduction in genital itch as measured by the genital itch numeric rating scale (NRS) (60\% vs. $8 \%$ ) compared with placebo. Safety outcomes were similar to the overall safety profile of ixekizumab, with the most common adverse events including diarrhea, injection site reactions, nasopharyngitis, upper respiratory tract infections, and headaches.

Two cases (grade 5) reported that oral dapsone given $100 \mathrm{mg}$ daily was found to be successful in clearing psoriasis lesions within 4 weeks, without any reported adverse events $[22,23]$. Mycophenolate mofetil and oral doxepin have both been reported as successful treatments for genital psoriasis in one case each as well $[14,23]$. Methotrexate $7.5-20 \mathrm{mg}$ weekly improved genital symptoms in two of four genital psoriasis patients [14, 18, 23, 24]. However, methotrexate use was associated with gastrointestinal disturbance, headache, insomnia, and urinary tract infections. There is one report of genital pustular psoriasis clearance 
after initiation of chlorpromazine for treatment of a concurrent manic episode [25]. Adalimumab has also been shown in one case report to result in clearance of genital psoriasis by 6 months without adverse effects [24]. Efalizumab considerably improved genital pruritus in 9 patients (grade 4 ) given at a dose of $1 \mathrm{mg} / \mathrm{kg}$ weekly for 12 weeks [26]. However, 2 of 55 patients in this study experienced adverse events requiring treatment discontinuation within 12 weeks (psoriasis flare and neurologic symptoms), and 7 patients described self-limited treatment-associated papular psoriasis. Efalizumab has since been removed from the market because of safety concerns [27].

\section{Treatment of Genital Psoriasis in the Pediatric Population}

A total of 12 articles examined treatments for genital psoriasis in infants and children (Table 4). Three of these articles were open-label studies (grade 4), while the remaining ten were case reports (grade 5) describing the effects of treatment on pediatric patients. Treatment outcomes were described for a total of 126 patients. Mild, topical coal tar preparations were effective in clearing genital lesions among 91 pediatric patients from two case series $[16,28]$.

Topical corticosteroid-based regimens led to successful treatment outcomes in 37 cases. Lowpotency topical steroids were used in 26 patients; moderate- and high-potency steroids were used in 6 patients and 1 patient, respectively. Successful treatment in six patients also included topical antifungal medications, primarily ketoconazole cream and clotrimazole cream. There was one case report (grade 5) of complete resolution of psoriatic lesions with topical pimecrolimus $1 \%$ ointment treatment [29]. All of the therapies used in children were well tolerated, without any significant adverse events reported.

\section{DISCUSSION}

In the past several years, there has been a moderate increase in studies assessing treatments for genital psoriasis. At the time of the last published review on this topic in 2011, only 6 case reports and 1 open-label study described the effects of therapies for genital psoriasis, while 24 articles reflected expert onion on treatment for this disease [3]. In our analysis, we found 1 randomized controlled trial (grade 1), 11 open-label studies (grade 4), and 26 case reports (grade 5) describing the efficacy and safety of topical and systemic treatments for genital psoriasis. Various therapies have been shown to be effective for genital psoriasis in case reports and case series, but high-quality evidence in the form of randomized controlled trials remains inadequate for genital psoriasis treatments.

Low-to-mid-potency topical corticosteroids are recommended as the first-line treatment for genital psoriasis [30] (grade of recommendation: D) and are commonly reported in the literature to be a critical component of treatment for these lesions. However, topical corticosteroids are generally approached with great caution for genital psoriasis patients because of the unique environment of the genitalia [31]. The thin skin and constant occlusion of this environment cause topical medications to have increased penetration in the groin area, which is a particular problem for infants, who have a high surface area-to-body mass ratio, predisposing them to systemic side effects. Mild topical corticosteroids may not be potent enough to induce a clinically significant response in some patients $[11,32]$ and are often used in combination with second-line topical therapies to yield clinical benefit (Table 2). Moderate-to-high-potency corticosteroids have been used effectively in adults and children with genital psoriasis, both as monotherapy and in combination with other topical agents, without reports of significant adverse effects (Table 2). There was a lack of reporting on adverse effects from topical corticosteroids in studies included our analysis; therefore, there is not enough evidence to determine whether there were no side effects with these therapies or if they simply were not mentioned. From the existing evidence, topical corticosteroids continue to be recommended as first-line treatment 


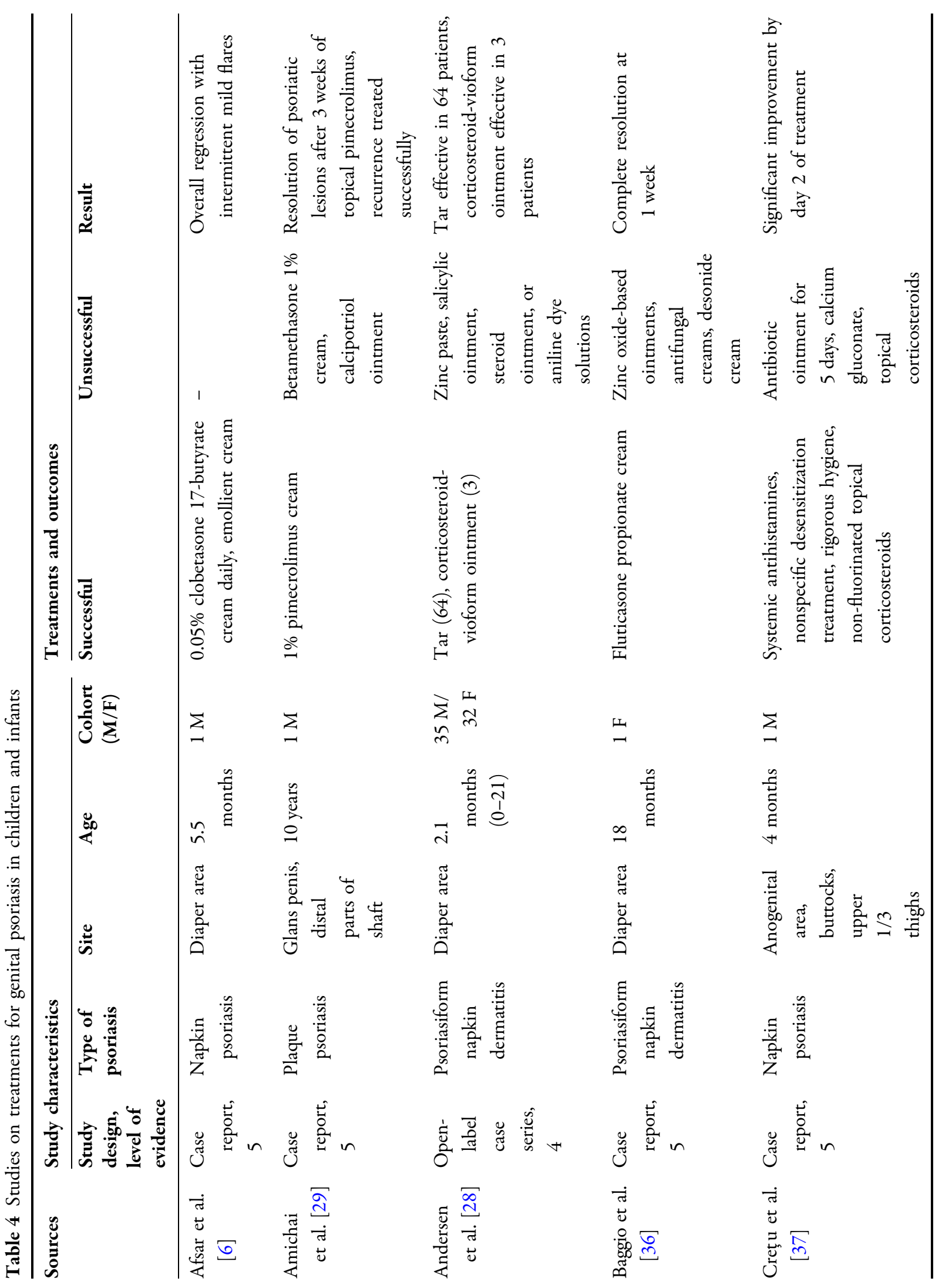




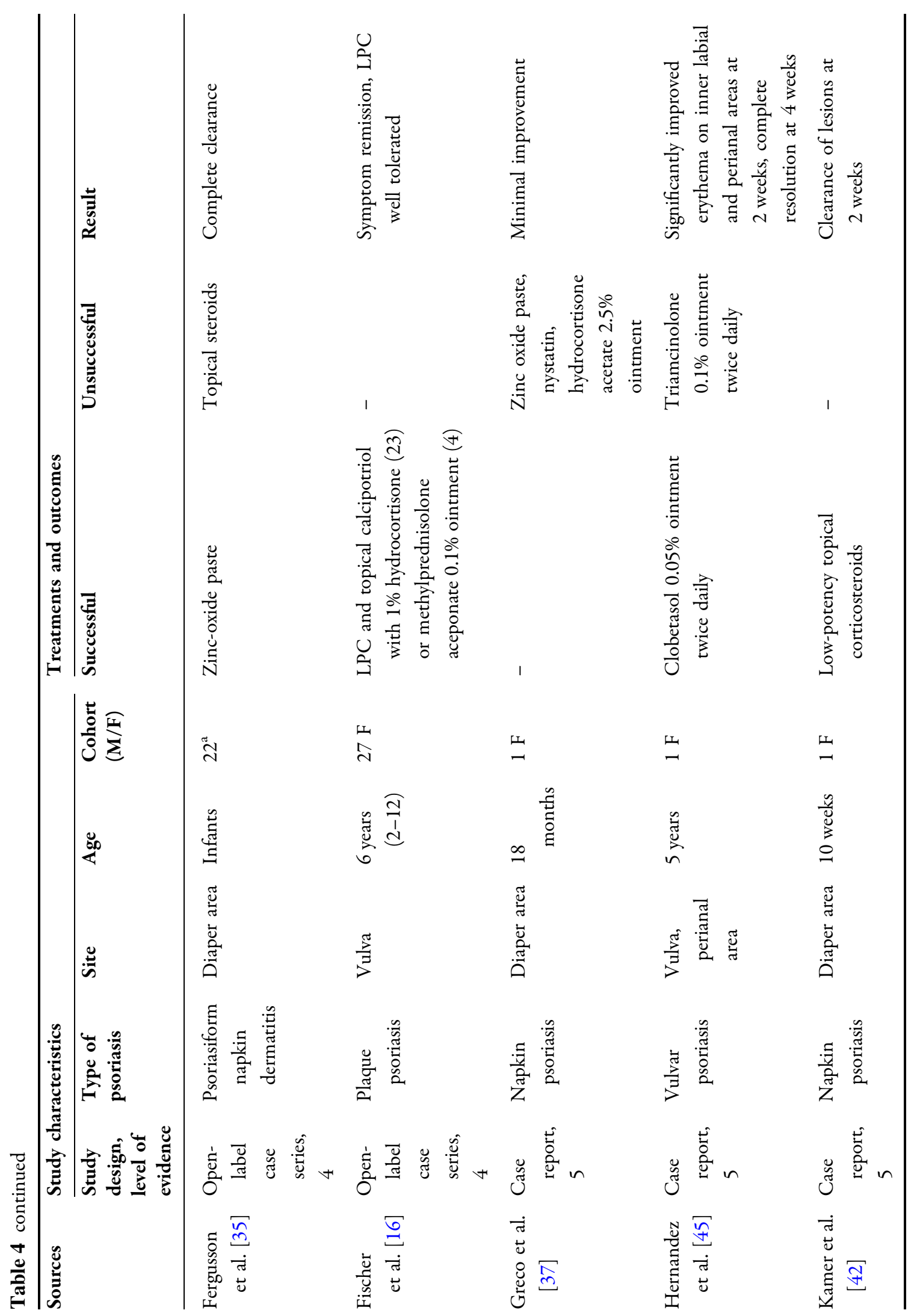




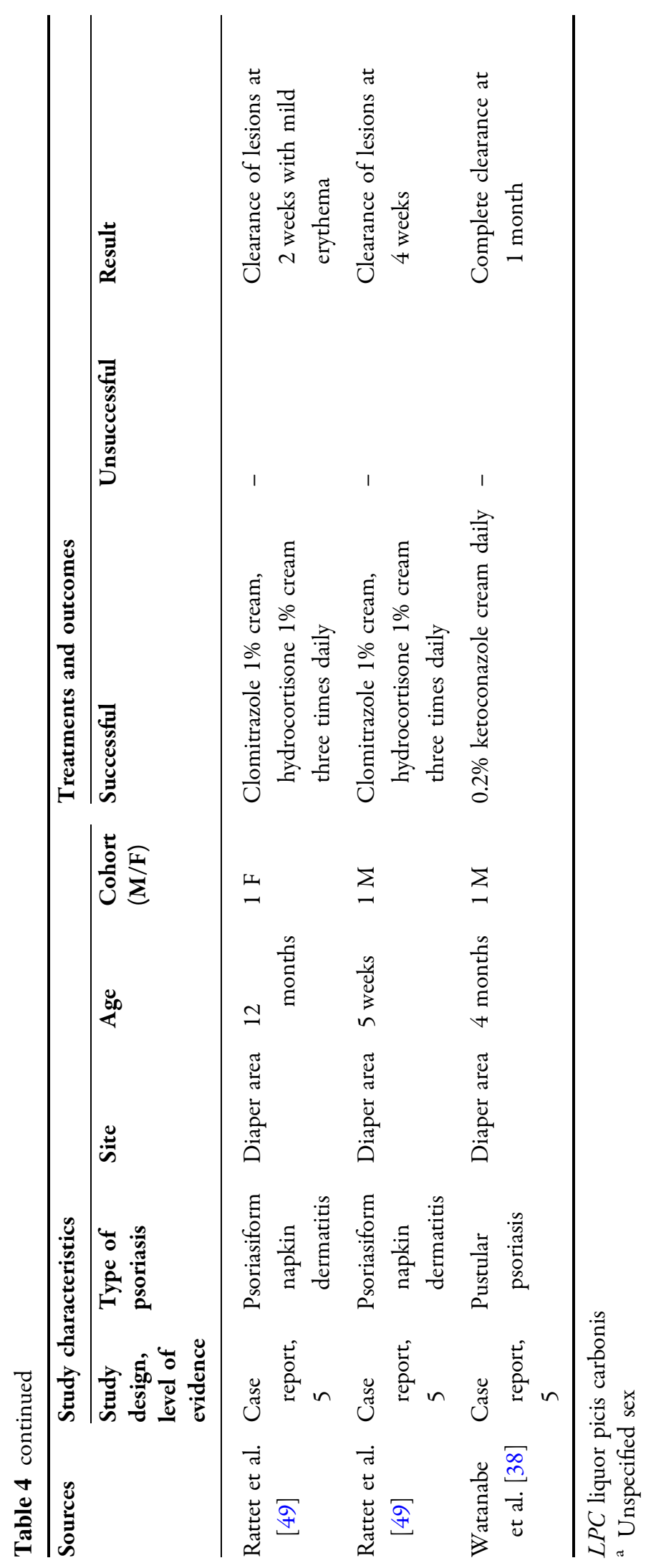


for genital psoriasis (grade of recommendation: C).

The data in this analysis do not show superior efficacy for nonsteroidal topical treatments compared with topical corticosteroids for the treatment of genital psoriasis (Table 2). Topical calcineurin inhibitors did improve genital psoriasis in several patients and were fairly well tolerated. Mild burning or pruritus can be associated with using these treatments in the sensitive groin region, but these symptoms are often manageable and limited in duration [33]. Topical coal tar preparations demonstrate efficacy in both adults and children with genital lesions and are not associated with significant adverse effects. Vitamin D analogs are sometimes recommended for patients with general psoriasis (grade of recommendation: D), but this is less reported in the literature [11, 30]. However, these nonsteroidal topical therapies may increase the risk for lymphoma, be more irritating, and be more costly than topical corticosteroids [34]. Topical calcineurin inhibitors, coal tar preparations, and vitamin $\mathrm{D}$ analogs may thus be used as second-line therapies for psoriasis lesions in the genital area (grade of recommendation: $\mathrm{C}$ ).

Systemic therapies such as dapsone and methotrexate can work well for patients with genital lesions and should be considered for patients with debilitating quality of life impairment (grade of recommendation: C) [30]. Our analysis did not find any evidence on the use of other traditional systemic agents, such as oral cyclosporine, acitretin, or apremilast, specifically for genital psoriasis. Although numerous effective biologics are available for the treatment of psoriasis, there is only one published clinical trial result on the efficacy of currently approved biologics specifically for genital psoriasis.

A recent study has shown ixekizumab to have high efficacy specifically for genital psoriasis, with rapid improvement seen as early as 1 week into treatment [21]. This medication significantly improves genital lesion appearance, genital itch, sexual health, and quality of life and may be a promising solution for patients suffering from recalcitrant genital psoriasis. Ixekizumab is currently the only medication with FDA labeling specifically mentioning genital psoriasis (grade of recommendation: B).

Although not specifically addressed in the majority of articles in our analysis, good hygiene and reduction of friction are essential first-line measures for the treatment of genital psoriasis patients (grade of recommendation: D) [11]. Gentle, non-soap cleansers are recommended to keep the genitals clean without irritating the area, and patients should be advised to wear loose-fitting, unrestrictive clothing to avoid koebnerization and further irritation [30]. Patients with genital psoriasis should always use lubricant or lubricated condoms with any sexual activity to avoid exacerbation of genital symptoms. In combination with proper pharmacologic therapy, these supportive measures are necessary for minimizing the impact of genital psoriasis.

Despite increased research into genital psoriasis in recent years, the optimal treatment approach for affected patients remains unclear. Overall, available evidence is limited, especially regarding the efficacy of systemic agents for genital psoriasis. This is most likely because systemic treatments are indicated for moderateto-severe psoriasis, and efficacy evaluations typically do not specifically assess genital symptoms. Genital psoriasis is ill defined, varies in characterization throughout the literature, and is not distinguished from inverse psoriasis in several studies. The existing literature thus uses various different measures to evaluate treatment efficacy or assess symptom improvement qualitatively so studies can be difficult to compare. The introduction of novel assessment tools for genital psoriasis will facilitate a greater understanding of how various treatments compare.

Additionally, most studies included in our analysis did not assess or report safety data or side effects with treatment, which is especially important for the sensitive genital area. Most recommendations for treating genital psoriasis are based on case reports or expert opinion only, and randomized controlled trials for this disease are lacking $[3,11]$. Larger sample sizes and controlled studies are needed to properly assess the safety and efficacy of treatments for 
genital psoriasis to better understand the optimal management approach for these patients.

\section{CONCLUSIONS}

Recently, a growing number of studies have evaluated the efficacy of various treatments specifically for genital psoriasis, including one randomized clinical trial for a biologic agent [3]. A variety of topical therapies have shown varying success for treatment of genital psoriasis, while far fewer systemic and biologic therapies have been evaluated for genital psoriasis. Further inquiry into the optimal treatment regimen for genital psoriasis is necessary.

\section{ACKNOWLEDGEMENTS}

Funding. No funding or sponsorship was received for this study or publication of this article. Wilson Liao is funded in part by grants from the National Institutes of Health (R01AR065174, U01AI119125).

Authorship. All named authors meet the International Committee of Medical Journal Editors (ICMJE) criteria for authorship for this article, take responsibility for the integrity of the work as a whole, and have given their approval for this version to be published.

Disclosures. Kristen M Beck, Eric J Yang, Isabelle M Sanchez, and Wilson Liao have nothing to disclose.

Compliance with Ethics Guidelines. The article is based on previously conducted studies and does not contain any studies with human participants or animals performed by any of the authors.

Open Access. This article is distributed under the terms of the Creative Commons Attribution-NonCommercial 4.0 International License (http://creativecommons.org/licenses/ by-nc/4.0/), which permits any noncommercial use, distribution, and reproduction in any medium, provided you give appropriate credit to the original author(s) and the source, provide a link to the Creative Commons license, and indicate if changes were made.

\section{REFERENCES}

1. Meeuwis KAP, Potts Bleakman A, van de Kerkhof PCM, Dutronc Y, Henneges C, Kornberg LJ, Menter A. Prevalence of genital psoriasis in patients with psoriasis. J Dermatol Treat. 2018:1-7.

2. Wang G, Li C, Gao T, Liu Y. Clinical analysis of 48 cases of inverse psoriasis: a hospital-based study. Eur J Dermatol. 2005;15:176-8.

3. Meeuwis KA, de Hullu JA, Massuger LF, van de Kerkhof PC, van Rossum MM. Genital psoriasis: a systematic literature review on this hidden skin disease. Acta Derm Venereol. 2011;91:5-11.

4. Ryan C, Sadlier M, De Vol E, Patel M, Lloyd AA, Day A, Lally A, Kirby B, Menter A. Genital psoriasis is associated with significant impairment in quality of life and sexual functioning. J Am Acad Dermatol. $2015 ; 72: 978-83$.

5. Morris A, Rogers M, Fischer G, Williams K. Childhood psoriasis: a clinical review of 1262 cases. Pediatr Dermatol. 2001;18:188-98.

6. Afsar FS, Uysal SS, Salis FM, Calli AO. Napkin psoriasis. Pediatr Int. 2016;58:420-2.

7. Meeuwis KA, de Hullu JA, van de Nieuwenhof HP, Evers AW, Massuger LF, van de Kerkhof PC, van Rossum MM. Quality of life and sexual health in patients with genital psoriasis. $\mathrm{Br} \mathrm{J}$ Dermatol. 2011;164:1247-55.

8. Zamirska A, Reich A, Berny-Moreno J, Salomon J, Szepietowski JC. Vulvar pruritus and burning sensation in women with psoriasis. Acta Derm Venereol. 2008;88:132-5.

9. Cather JC, Ryan C, Meeuwis K, Potts Bleakman AJ, Naegeli AN, Edson-Heredia E, Poon JL, Jones C, Wallace AN, Guenther L, Fretzin S. Patients' perspectives on the impact of genital psoriasis: a qualitative study. Dermatol Ther (Heidelb). 2017;7:447-61.

10. Meeuwis KA, van de Kerkhof PC, Massuger LF, de Hullu JA, van Rossum MM. Patients' experience of psoriasis in the genital area. Dermatology. 2012;224:271-6. 
11. Menter A, Korman NJ, Elmets CA, Feldman SR, Gelfand JM, Gordon KB, Gottlieb A, Koo JY, Lebwohl M, Leonardi CL, Lim HW, Van Voorhees AS, Beutner KR, Ryan C, Bhushan R. Guidelines of care for the management of psoriasis and psoriatic arthritis: section 6 . Guidelines of care for the treatment of psoriasis and psoriatic arthritis: case-based presentations and evidence-based conclusions. J Am Acad Dermatol. 2011;65:137-74.

12. Farage M, Maibach HI. The vulvar epithelium differs from the skin: implications for cutaneous testing to address topical vulvar exposures. Contact Dermatitis. 2004;51:201-9.

13. Howick J, Chalmers I, Glasziou P, Greenhalgh T, Heneghan C, Liberati A, Moschetti I, Phillips B, Thornton H. The 2011 Oxford CEBM levels of evidence (introductory document). Oxford Centre for Evidence-Based Medicine. 2011.

14. Albert S, Neill S, Derrick EK, Calonje E. Psoriasis associated with vulval scarring. Clin Exp Dermatol. 2004;29:354-6.

15. Jemec GB, Baadsgaard O. Effect of cyclosporine on genital psoriasis and lichen planus. J Am Acad Dermatol. 1993;29:1048-9.

16. Fischer G. Chronic vulvitis in pre-pubertal girls. Aust J Dermatol. 2010;51:118-23.

17. Meeuwis KA, de Hullu JA, IntHout J, Hendriks IM, Sparreboom EE, Massuger LF, van de Kerkhof PC, van Rossum MM. Genital psoriasis awareness program: physical and psychological care for patients with genital psoriasis. Acta Derm Venereol. 2015;95:211-6.

18. Kapila S, Bradford J, Fischer G. Vulvar psoriasis in adults and children: a clinical audit of 194 cases and review of the literature. J Lower Genit Tract Dis. 2012;16:364-71.

19. Liao YH, Chiu HC, Tseng YS, Tsai TF. Comparison of cutaneous tolerance and efficacy of calcitriol 3 microg g(-1) ointment and tacrolimus $0.3 \mathrm{mg} g(-1)$ ointment in chronic plaque psoriasis involving facial or genitofemoral areas: a double-blind, randomized controlled trial. $\mathrm{Br} \mathrm{J}$ Dermatol. 2007; 157:1005-12.

20. TALTZ (ixekizumab) [package insert]. Indianapolis: Eli Lilly and Company. 2017.

21. Ryan C, Menter A, Guenther L, Blauvelt A, Bissonnette R, Yang F, Potts Bleakman A. Efficacy and safety of ixekizumab in a randomized, doubleblinded, placebo-controlled, phase $3 \mathrm{~b}$ clinical trial in patients with moderate-to-severe genital psoriasis. J Sexual Med. 2018;15:S6-7.
22. Singh N, Thappa DM. Circinate pustular psoriasis localized to glans penis mimicking 'circinate balanitis' and responsive to dapsone. Indian J Dermatol Venereol Leprol. 2008;74:388-9.

23. Guglielmetti A, Conlledo R, Bedoya J, Ianiszewski F, Correa J. Inverse psoriasis involving genital skin folds: successful therapy with dapsone. Dermatol Ther (Heidelb). 2012;2:15.

24. Jese R, Perdan-Pirkmajer K, Dolenc-Voljc M, Tomsic M. A case of inverse psoriasis successfully treated with adalimumab. Acta Dermatovenerol Alp Pannonica Adriat. 2014;23:21-3.

25. Shimamoto Y, Shimamoto H. Annular pustular psoriasis associated with affective psychosis. Cutis. 1990;45:439-42.

26. Cassano N, Mastrandrea V, Buquicchio R, Miracapillo A, Loconsole F, Filotico R, Vena GA. Efalizumab in moderate-to-severe plaque psoriasis: a retrospective case series analysis from clinical practice. J Biol Regul Homeost Agents. 2008;22:185-93.

27. Talamonti M, Teoli M, Botti E, Spallone G, Chimenti S, Costanzo A. Patients with moderate to severe plaque psoriasis: one year after the European Medicines Agency recommendation of efalizumab suspension. Dermatology. 2011;222:250-5.

28. Andersen SL, Thomsen K. Psoriasiform napkin dermatitis. Br J Dermatol. 1971;84:316-9.

29. Amichai B. Psoriasis of the glans penis in a child successfully treated with Elidel (pimecrolimus) cream. J Eur Acad Dermatol Venereol. 2004;18:742-3.

30. Menter A, Korman NJ, Elmets CA, Feldman SR, Gelfand JM, Gordon KB, Gottlieb AB, Koo JY, Lebwohl M, Lim HW, Van Voorhees AS, Beutner KR, Bhushan R. Guidelines of care for the management of psoriasis and psoriatic arthritis: section 4. Guidelines of care for the management and treatment of psoriasis with traditional systemic agents. J Am Acad Dermatol. 2009;61:451-85.

31. Kivelevitch D, Frieder J, Watson I, Paek SY, Menter MA. Pharmacotherapeutic approaches for treating psoriasis in difficult-to-treat areas. Expert Opin Pharmacother. 2018;19:561-75.

32. Czuczwar P, Stepniak A, Goren A, Wrona W, Paszkowski T, Pawlaczyk M, Piekarska-Myslinska D, Wozniak S, Pietrzak A. Genital psoriasis: a hidden multidisciplinary problem-a review of literature. Ginekol Pol. 2016;87:717-21.

33. Bissonnette R, Nigen S, Bolduc C. Efficacy and tolerability of topical tacrolimus ointment for the 
treatment of male genital psoriasis. J Cutan Med Surg. 2008;12:230-4.

34. Broeders JA, Ahmed Ali U, Fischer G. Systematic review and meta-analysis of randomized clinical trials (RCTs) comparing topical calcineurin inhibitors with topical corticosteroids for atopic dermatitis: a 15-year experience. J Am Acad Dermatol. 2016;75:410-419 (e413).

35. Fergusson AG, Fraser NG, Grant PW. Napkin dermatitis with psoriasiform "ide". A review of fiftytwo cases. Br J Dermatol. 1966;78:289-96.

36. Baggio R, Le Treut C, Darrieux L, Vareliette A, Safa G. Psoriasiform diaper rash possibly induced by oral propranolol in an 18-month-old girl with infantile hemangioma. Case Rep Dermatol. 2016;8:369-73.

37. Greco M, Chamlin SL. An 18-month-old girl with chronic diaper dermatitis. Psoriasis presenting in the diaper area. Pediatr Ann. 2006;35(79):82-3.

38. Watanabe M, Tabata N, Tagami H. Explosive diaper pustular psoriasis. Pediatr Dermatol. United States. 2002;19:564-5.

39. Foureur N, Vanzo B, Meaume S, Senet P. Prospective aetiological study of diaper dermatitis in the elderly. Br J Dermatol. 2006;155:941-6.

40. Yao XJ, Zhang TD. Psoriasis localized to the glans penis in a 37-year-old man. CMAJ. 2018;190:E747.

41. Usatine RP. Itchy rash in groin. J Fam Pract. 2016;65(11).

42. Kamer B, Pyziak K, Krawczyk T, Socha-Banasiak A, Rotsztejn H. A rare case of psoriasis resembling diaper dermatitis. Przeglad Pediatryczny. 2012;42:160-1.

43. Quan MB, Ruben BS. Pustular psoriasis limited to the penis. Int J Dermatol. 1996;35:202-4.
44. Weinrauch L, Katz M. Psoriasis vulgaris of labium majus. Cutis. 1986;38:333-4.

45. Hernandez M, Simms-Cendan J, Zendell K. Guttate psoriasis following streptococcal vulvovaginitis in a five-year-old girl. J Pediatr Adolesc Gynecol. 2015;28:e127-9.

46. Martin Ezquerra G, Sanchez Regana M, Herrera Acosta E, Umbert Millet P. Topical tacrolimus for the treatment of psoriasis on the face, genitalia, intertriginous areas and corporal plaques. J Drugs Dermatol. 2006;5:334-6.

47. Rallis E, Nasiopoulou A, Kouskoukis C, RoussakiSchulze A, Koumantaki E, Karpouzis A, Arvanitis A. Successful treatment of genital and facial psoriasis with tacrolimus ointment $0.1 \%$. Drugs Exp Clin Res. 2005;31:141-5.

48. Zampetti A, Gnarra M, Linder D, Digiuseppe MD, Carrino N, Feliciani C. Psoriatic pseudobalanitis circinata as a post-viral koebner phenomenon. Case Rep Dermatol. 2010;2:183-8.

49. Rattet JP, Headley JL, Barr RJ. Diaper dermatitis with psoriasiform ID eruption. Int $\mathrm{J}$ Dermatol. 1981;20:122-5.

50. Ryan C, Menter A, Guenther L, Blauvelt A, Bissonnette R, Meeuwis K, Sullivan J, Cather JC, Yosipovitch G, Gottlieb AB, Merola JF, Callis Duffin K, Fretzin S, Osuntokun OO, Burge R, Naegeli AN, Yang FE, Lin CY, Todd K, Potts Bleakman A. Efficacy and safety of ixekizumab in a randomized, doubleblinded, placebo-controlled phase $3 \mathrm{~b}$ study of patients with moderate-to-severe genital psoriasis. Br J Dermatol. 2018.

51. Sezer E, Lehman JS, Yalçın Ö, Tüfek İ, Keskin S, Durmaz EÖ, Sahin S. Oyster-shaped hyperkeratotic plaques on the penis. Dermatol Pract Concept. 2015;5(4):37-8. https://doi.org/10.5826/dpc.0504a09. 